\title{
Work Softening of Drawn Low Carbon Steel Bars
}

\author{
Maria Teresa Paulino Aguilar ${ }^{a^{*}}$, Elaine Carballo Siqueira Corrê ${ }^{a}$, \\ Waldemar Alfredo Monteiro $^{b}$, Nildemar Aparecido Messias Ferreira ${ }^{b}$, \\ Paulo Roberto Cetlin ${ }^{a}$ \\ ${ }^{a}$ Universidade Federal de Minas Gerais, Escola de Engenharia, \\ 30160-030 Belo Horizonte - MG, Brasil \\ ${ }^{b}$ IPEN-SP, Cidade Universitária Armando Salles Oliveira, \\ 05508-900 São Paulo - SP, Brasil
}

Received: November 18, 2000; Revised: March 7, 2001

\begin{abstract}
The work hardening of metals subjected to complex processing paths is different from that in monotonic deformation. Changes in the deformation mode can promote transients in the strain-hardening rate, leading to anomalous softening or hardening of the material. This paper investigates the influence of strain path changes on the tensile behavior of drawn $0.12 \%$ steel rods. Annealed or predrawn specimens were submitted to cyclic twisting and then tested in tension. The results show that the cyclic deformation causes changes in the mechanical behavior of the metal, and the effect will depend on the previous "history" of the material. Cyclic twisting causes hardening in annealed samples, but leads to softening of the drawn bars. These phenomena are in line with the corresponding substructural aspects.
\end{abstract}

Keywords: strain path, mechanical properties

\section{Introduction}

The work hardening behavior of metals submitted to a sequential association of plastic deformation in various directions or of distinct natures is different from that in monotonic deformation. Besides, changes in strain path can lead to transients in the work hardening of the material. A lower hardening than in monotonic processing or the softening of a work hardened metal can be observed under these circunstances ${ }^{1-9}$. The occurrence and the magnitude of each phenomenon depend on the magnitude of the strain path change, which is expressed by a parameter defined as the cosine of the angle between the two vectors which represent the two strain tensors ${ }^{7,8}$. It has also been observed that cyclic processing tends to remove or to minimize the hardening effects of previous deformations ${ }^{10-15}$. This unusual behavior has been associated with the dislocation restructuring $5,7,8,10,14,15$ and the strain localization in shear bands ${ }^{11}$.

The mechanical behavior related to strain path changes has been the subject of many studies ${ }^{16}$. However, most of the published results analyze the effects of the association of initial plane strain or rolling of sheets, followed by uniaxial tensile tests ${ }^{3-5,8,9}$. The initial cold forming by drawing, followed by cyclic torsion (at the end of the process or between successive stages), would be interesting in order to change the processing strain path and to control the final properties of the products. The present paper investigates the influence of cyclic torsion on the properties of annealed or drawn low carbon steel $(0.12 \% \mathrm{C})$.

\section{Material and Experimental}

A steel with $0.12 \% \mathrm{C}, 0.47 \% \mathrm{Mn}, 0.07 \% \mathrm{Si}, 0.003 \mathrm{Sn}$, $0.01 \% \mathrm{Mo}, 0.016 \% \mathrm{P}$ and $0.013 \% \mathrm{~S}$ was used in the experiments. Specimens (cylindrical rods with $6.4 \mathrm{~mm}$ initial diameter) were annealed in vacuum at $850{ }^{\circ} \mathrm{C}$ during 2400 s. Final material homogeneity was verified through metalography and Vickers hardness. Four different experimental schedules were used to examine the effects of the cyclic deformation on the subsequent tensile test: (a) annealed samples were tested in tension, (b) some annealed

*e-mail: teresa@demc.ufmg.br

Trabalho apresentado no $14^{\circ}$ CBECIMAT, Águas de São Pedro, Dezembro 2000. 
samples were directly submitted to cyclic torsion followed by tension, (c) some specimens were drawn in one or two passes and then subjected to tensile test, and (d) pre-drawn bars (one or two passes) were submitted to cyclic torsion followed by tension.

The drawing was performed in a hydraulic draw bench, at a speed of $17 \mathrm{~mm} / \mathrm{s}$, using tungsten carbide dies with semi-angles $8^{\circ}$ and $20^{\circ}$. The lubrication was performed with a molybdenum disulfide paste. Two reductions in area per pass were used: 8 and 20\%. Cyclic twisting was manually completed in a specially adapted bench lathe. Torsion was applied in 10 cycles, with a strain amplitude of $2.8 \%$. Since the drawn bars diameter varied for the two pre-deformation conditions, it was necessary to use specific torsion angles for each case in order to maintain the same cyclic deformation. Tensile tests were carried out on a machine under total strain amplitude control.

The experiments were completed at room temperature, and the specimens were stored below $0{ }^{\circ} \mathrm{C}$ between the deformation stages, in order to prevent the effects of static strain aging. Each test was repeated at least two times. Strain rates were similar in all experiments $\left(\sim 0.002 \mathrm{~s}^{-1}\right)$. This was necessary because changes in strain rates could produce work softening ${ }^{1}$.

\section{Results and Discussion}

Figures from 1 to 3 show the experimental results of tensile tests for annealed, annealed/cyclically twisted, drawn and drawn /cyclically twisted samples (semi-angle $8^{\circ}$ and $20^{\circ}$ and reduction in area of $8 \%$ ). Results for material drawn in one and two passes are shown. True stress-true strain curves and strain hardening rate-true strain curves are presented. Cyclic deformation increased the flow stresses of the initially annealed sample. On the other hand, it promoted a decrease in the strain hardening rate. For prestrained samples, the effect of the cyclic deformation was the opposite. Pre-drawn bars subjected to cyclic torsion presented lower flow stresses and higher hardening rates than drawn samples. Besides these results, cyclic torsion

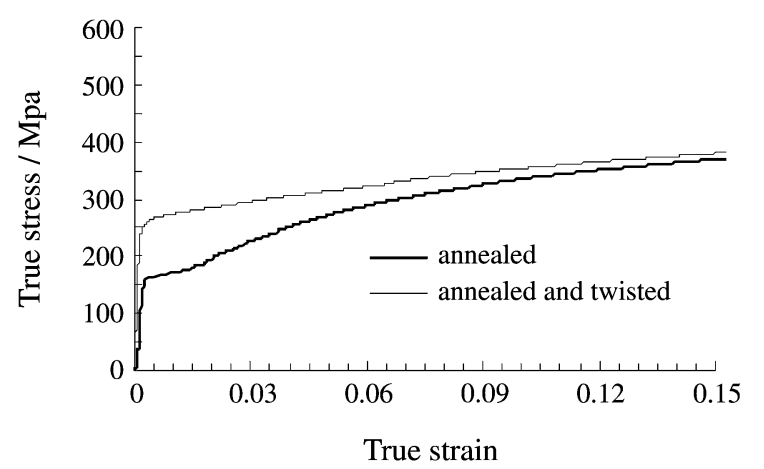

tends to remove the transient reductions in strain hardening rates, which were observed for single pass drawn bars.

Similar experiments were performed for samples drawn with reduction in area of $20 \%$ (Figs. 4 and 5). As it was observed for samples drawn with reduction in area of $8 \%$, cyclic torsion led to a decrease in flow stresses. Strain hardening rate-true strain curves are not displayed because tensile elongation for these samples was very small and it was not possible to compare the results.

These results confirm that the hardening behavior depends on the strain path and that cyclic processing tends to remove or minimize the effects of previous deformation. The work softening magnitude doesn't depend on the die semi-angle, and the observed effects are more pronounced for the material drawn in two passes or with $20 \%$ reduction in area per pass.

The observation of the above figures shows that cyclic torsion was able to reduce the hardening effects of the second 8 or $20 \%$ drawing pass, bringing back the material to a condition similar to that for single pass drawing.

The dislocation substructures were observed using transmission electron microscopy (TEM) in samples submitted to different strain paths. Figures 6, 7 and 8 show the dislocation structure of the material close to the rod surface, for the annealed, drawn and drawn/cyclically twisted material, respectively. In spite of the fact that these results show structures obtained for single pass drawn samples, with $8^{\circ}$ and $20 \%$, they are general examples of the influence of the cyclic twisting in the dislocation structure. The cellular dislocation structure is not observed on annealed samples (Fig. 6), which display very low dislocation density. Drawing (Fig. 7) causes intense dislocation multiplication, associated with irregular dislocation cells displaying relatively intense tangles in their interior. The presence of parallel dislocation walls is observed and indicates the direction of the applied shear stress. Cyclic torsion (Fig. 8) drastically reduces the presence of the tangles and causes an evolution of the cells to a larger size, associated to a "blocky" shape. The parallel aspect is not observed.

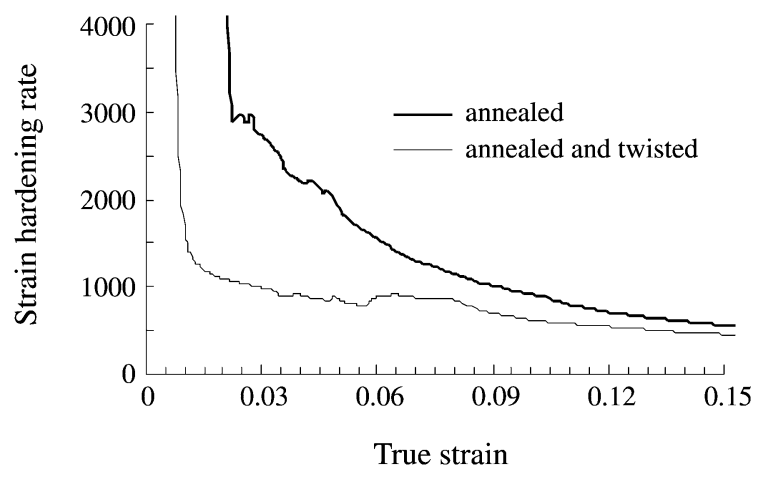

Figure 1. Effect of cyclic torsion on the hardening behavior of annealed samples. 

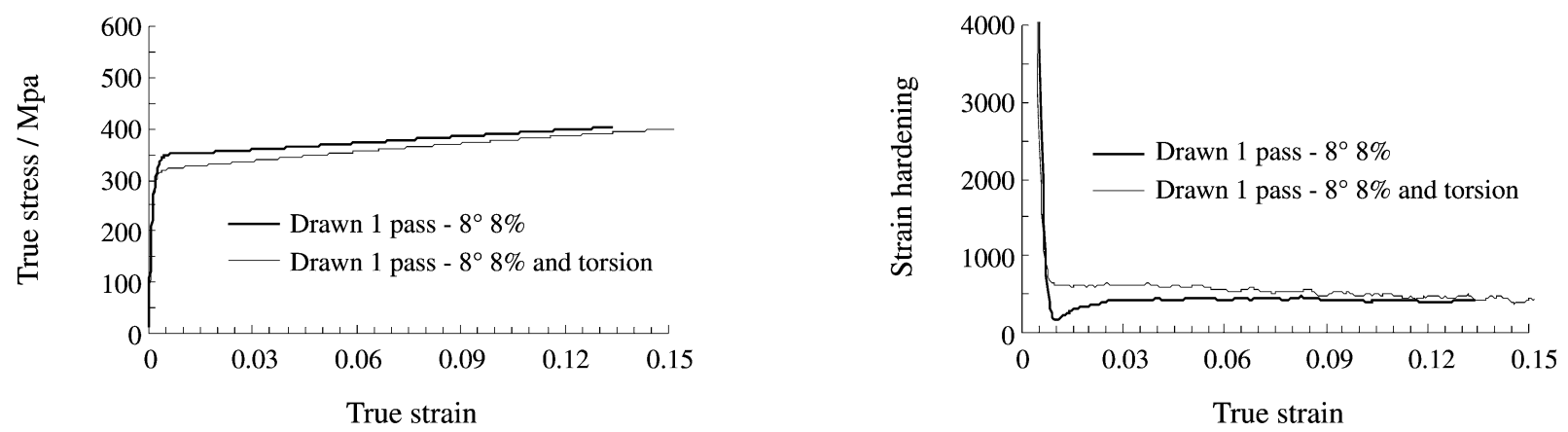

(a)
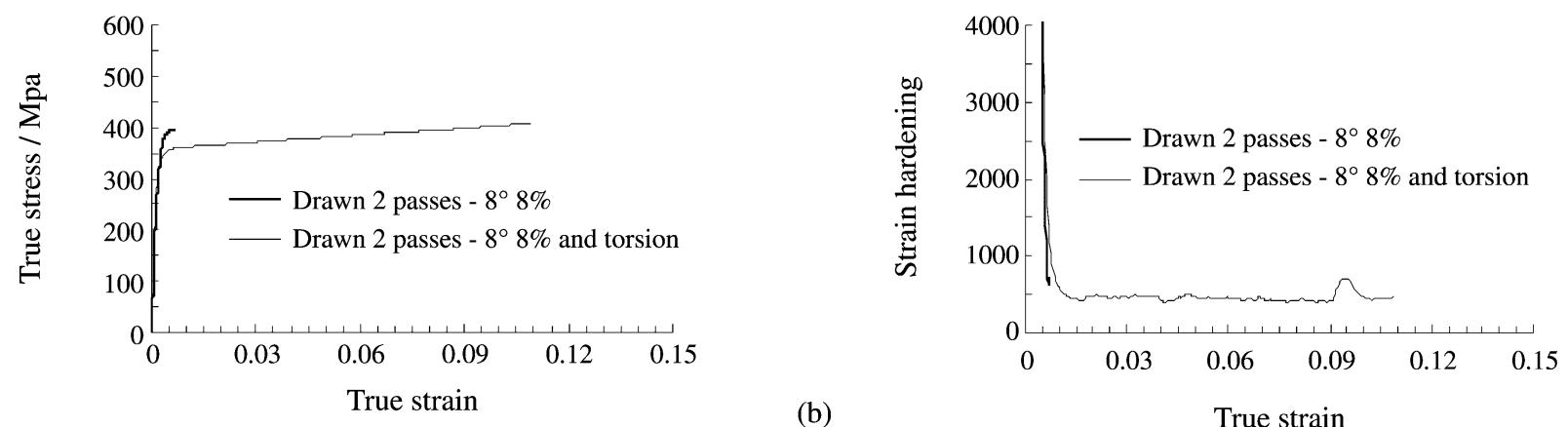

(b)

True strain

Figure 2. Effect of cyclic torsion on the hardening behavior of drawn (semi-angle $8^{\circ}$ and reduction in area of $8 \%$ ) samples: (a) 1 pass and (b) 2 passes.
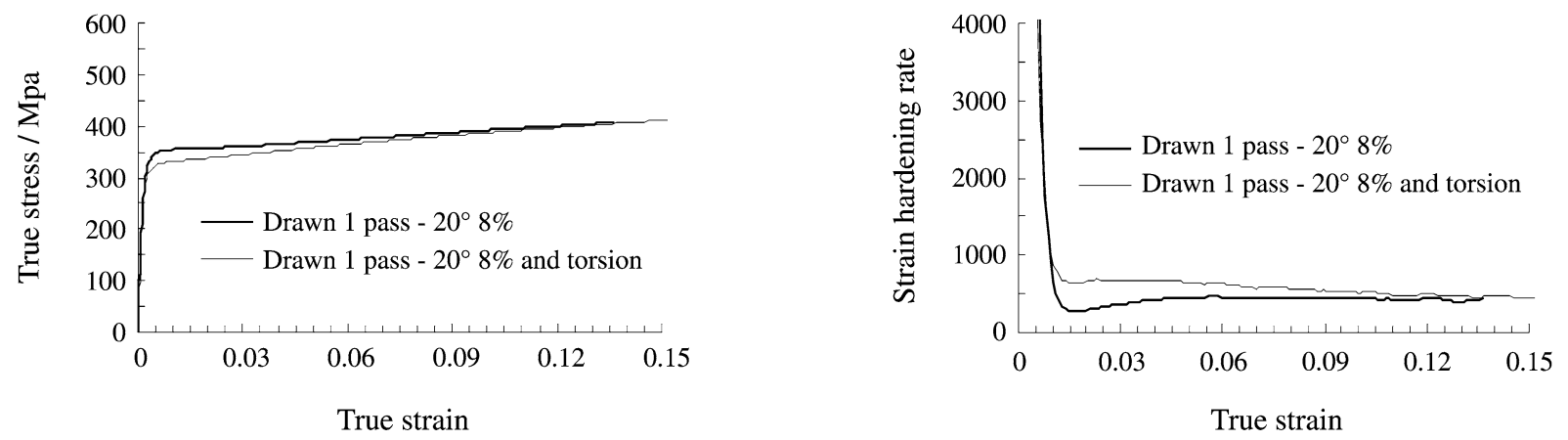

(a)
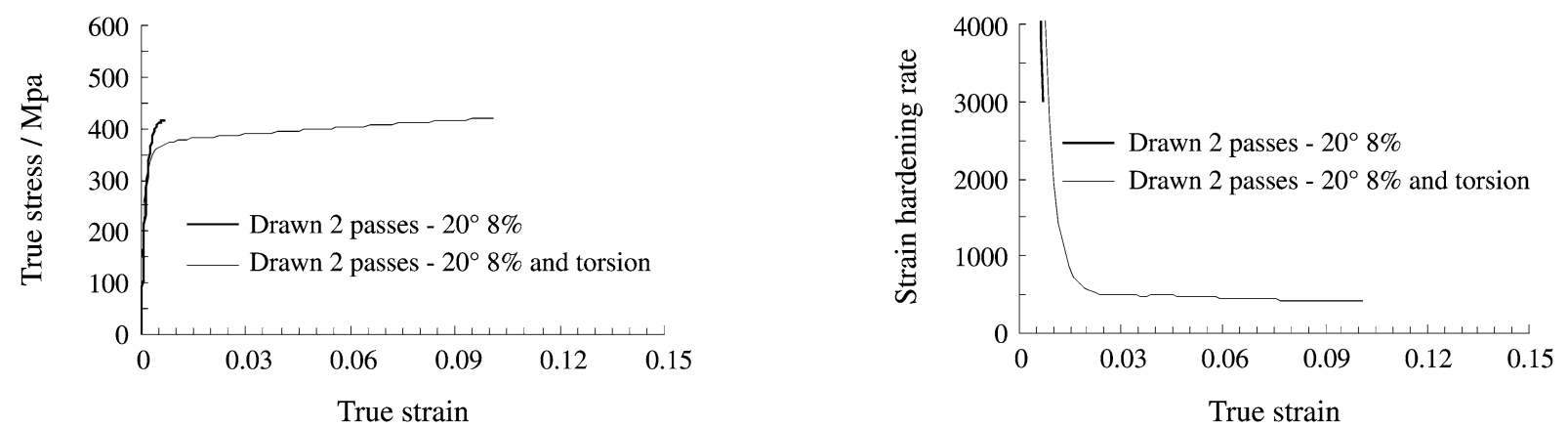

(b)

Figure 3. Effect of cyclic torsion on the hardening behavior of drawn (semi-angle $8^{\circ}$ and reduction in area of 20\%) samples: (a) 1 pass and (b) 2 passes. 


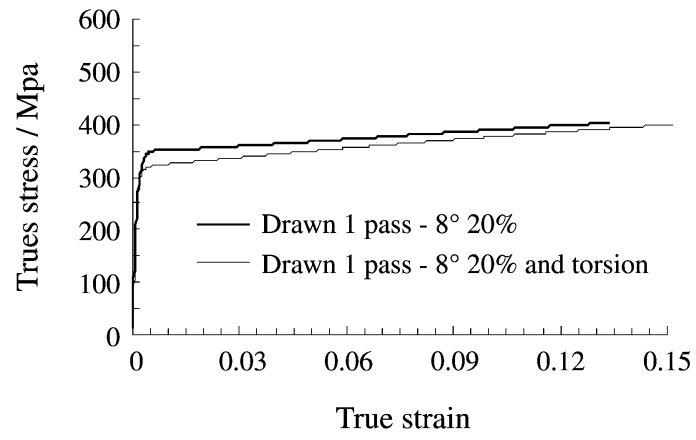

(a)

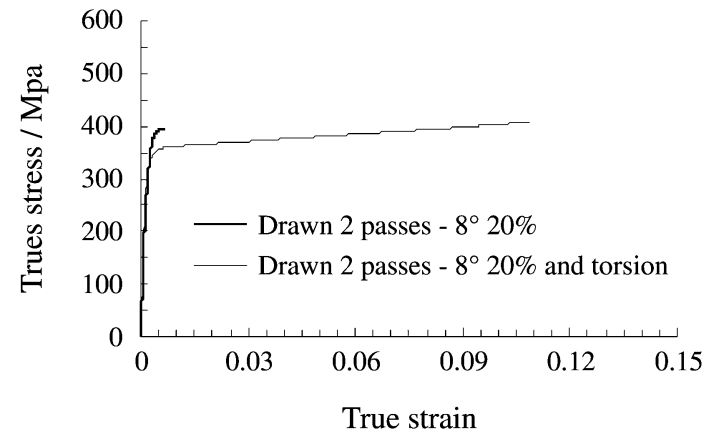

(b)

Figure 4. Effect of cyclic torsion on the hardening behavior of drawn (semi-angle $20^{\circ}$ and reduction in area of $8 \%$ ) samples: (a) 1 pass and (b) 2 passes.

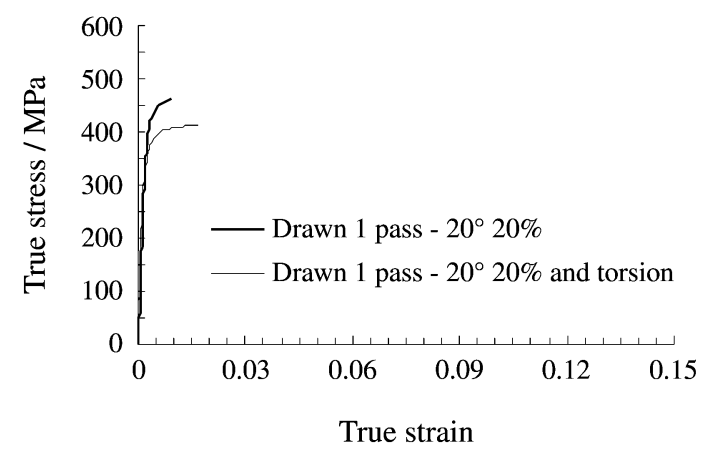

(a)

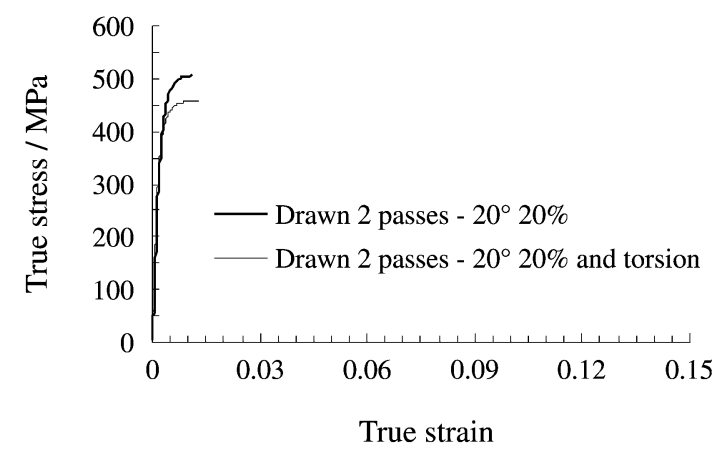

(b)

Figure 5. Effect of cyclic torsion on the hardening behavior of drawn (semi-angle $20^{\circ}$ and reduction in area of 20\%) samples: (a) 1 pass and (b) 2 passes.

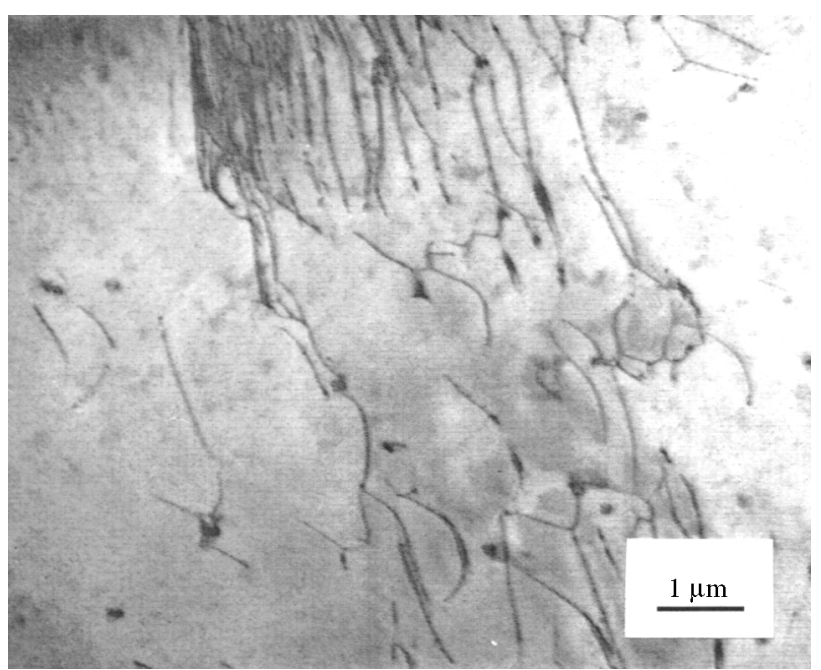

Figure 6. TEM observation of dislocations structure of a specimen annealed.

Cyclic torsion promotes dynamic recovery in the prestrained samples, with the consequent work softening indicated in Figs. 2-5. The process is associated with an oscillating movement of isolated dislocations, leading to a low level of tangling. Besides, the existing initial dislocation structure is modified, leading to dislocation annihilation and the relaxation of stress fields caused by dislocation

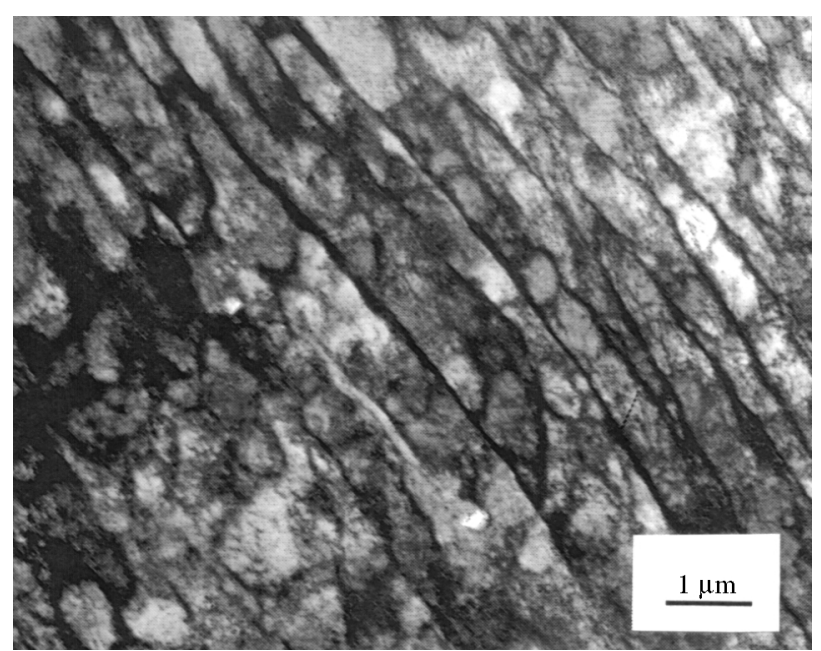

Figure 7. TEM observation of dislocations structure of a specimen drawn in one pass, $8^{\circ}$ and $20 \%$.

walls. These observations are similar to those described in the literature for strain path changes in sheets ${ }^{8}$.

\section{Conclusions}

Cyclic deformation promotes a hardening and a decrease on the strain hardening rate in annealed samples of carbon steel. 


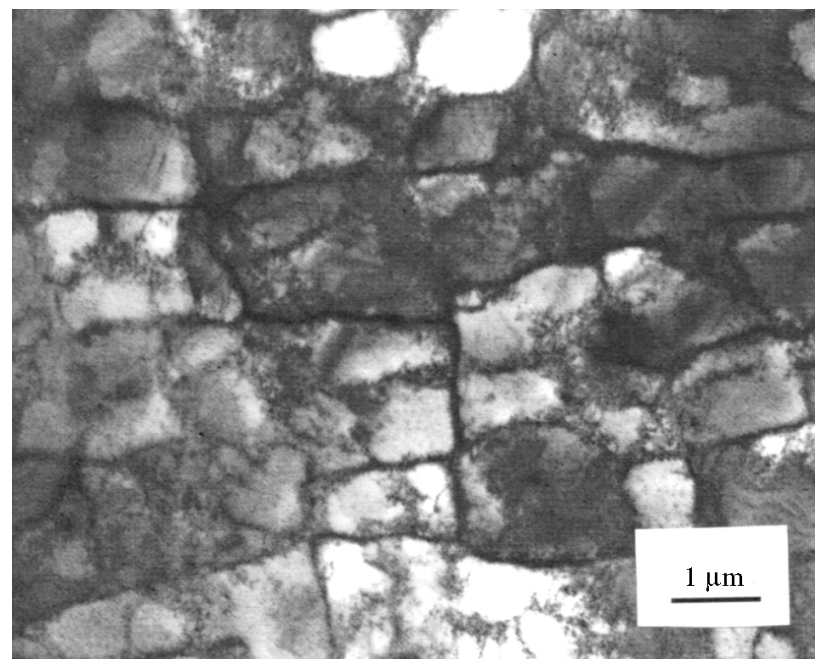

Figure 8. TEM observation of dislocations structure of a specimen drawn in one pass, $8^{\circ}$ and $20 \%$, and cyclically twisted.

Cyclic torsion softens previously drawn material. This effect is more pronounced for the two passes drawn material with $20 \%$ reduction in area. The softening magnitude seems to be in depend of the die semi-angle.

The mechanical behavior of the metal which underwent a double drawing pass and cyclic twisting is similar to that drawn in one pass.

The annealed material presents low dislocation density. Drawing promotes a parallel cellular dislocation structure and each cell displays intense dislocation tangles in their interior. Cyclic torsion causes a rearrangement of the dislocation structure in the drawn material that reduces the dislocation tangles inside the cells, which become larger.

\section{Acknowledgments}

The authors are thankful to CDTN/CNEN (Centro de Desenvolvimento de Tecnologia Nuclear/Comissão Nacional de Energia Nuclear) for the annealing of the specimens, to Belgo Mineira Bekaert Artefatos for supplying the drawing dies, and to CNPQ (Conselho Nacional de Desen- volvimento Científico e Tecnológico) and PRONEX (Programa de Núcleos de Excelência) for the financial support.

\section{References}

1. Backofen, W.A.; Ghosh, A.K. Metallurgical Transactions, v. 4, p. 1113-1123, 1973.

2.Laukonis, J.V.; Ghosh, A.K. Metallurgical Transactions, v. 9(A), p. 1849-1856, 1978.

3. Wagoner, R.H. Metallurgical Transactions, v. 13(A), p. 1491-1500, 1982.

4. Thomsen, E.G. Transactions of the ASME - Journal of Engineering Materials and Technology, v. 105, p. 178-181, 1983.

5. Wilson, D.V.; Zandrahimi, M.; Roberts, W.T. Acta Metallurgica, v. 38, n. 2, p. 215-2260, 1994.

6. Sillekens, W.H.; Dautzenberg, J.H.; Kals, J.A.G. Annals of the CIRP, v. 40, p. 255-258, 1991.

7. Fernandes, J.V.; Vieira, M.F. Metallurgical and Materials Transactions, v. 28(A), p. 1997-1169, 1997.

8. Wilson, D.V.; Bate, P.S. Acta Metallurgica Materialia, v. 42, n. 4, p. 1099-1111, 1994.

9. Doucet, A.B.; Wagoner, R.H. Metallurgical Transactions, v. 20(A), p. 1483-1493, 1989.

10. Armstrong, P.E.; Hockett, J.E.; Sherby, O.D. Journal of the Mechanics and Physics of Solids, v. 30, p. 37-58, 1982.

11. Richert, M.; Korbel, A. Journal of Materials Processing Technology, v. 53, p. 331-340, 1995.

12. Polakowski, N.H.; Palchoudhuri, A. Proc. ASTM, v. 54, p. 701-716, 1994.

13. Coffin, L.F.; Tavernelli, J.F. Transactions of the Metallurgical Society of AIME, v. 215, p. 784-807, 1959.

13. Yuebo, X.; Zhonggung, W.; Xiukui, D. Metallurgica Sinica, v. (A)2, n. 1, p. 1-6, 1989.

14. Sarma, V.S.; Padmanabhan, K.A. Journal of Materials Science Letters, v. 16, p. 1495-1498, 1997.

15. Fernandes, J.V.; Rodrigues, D.M.; Menees, L.F.; Vieira, M.F. International Journal of Plasticity, v. 14, n. 6, p. 537-550, 1998. 